\title{
Estatística espacial de varredura na detecção de áreas de risco para a cisticercose bovina no estado da Bahia
}

[Spatial scan statistic in the detection of risk areas for bovine cysticercosis in the state of Bahia]

\author{
M.E. Bavia ${ }^{1}$, D.D.M.T. Carneiro ${ }^{1}$, L.L. Cardim $^{1 *}$, M.M.N. Silva ${ }^{1}$, M.S. Martins ${ }^{2}$ \\ ${ }^{1}$ Escola de Medicina Veterinária - Universidade Federal da Bahia - Salvador, BA \\ ${ }^{2}$ School of Veterinary Medicine - Louisiana State University
}

\begin{abstract}
RESUMO
No intuito de classificar a distribuição geográfica da procedência dos animais infectados e mensurar as áreas quanto ao risco de se contrair a cisticercose bovina, foi utilizada a análise espacial de varredura para identificação de aglomerados de risco a partir dos casos positivos para o Cysticercus bovis registrados no período de 2006 a 2007, provenientes de seis matadouros frigoríficos do Serviço de Inspeção Federal, distribuídos para fins administrativos em Territórios de Identidade do estado da Bahia. O número de bovinos abatidos foi de 825.951, dentre os quais (0,7\%) 5.395 foram diagnosticados positivos para a doença, mediante a inspeção post mortem dos animais. A análise espacial de varredura, por meio do teste da razão de verossimilhança, demonstrou que a distribuição da cisticercose bovina se concentra, com menor probabilidade de ter ocorrido ao acaso, em área geográfica definida, com risco estimado em 13,6, englobando 101 municípios do estado pertencentes aos territórios de Itapetinga, Litoral Sul, Médio Rio de Contas, Vitória da Conquista e Extremo Sul.
\end{abstract}

Palavras-chave: cisticercose bovina, análise espacial, distribuição geográfica

\begin{abstract}
In order to identify the spatial geographical distribution of the infected animals and measure the areas under risk of contracting bovine cysticercosis, spatial scan analysis was used to identify clusters of positive bovine for Cysticercus bovis recorded in the period from 2006 to 2007, from six slaughterhouses under the Federal Inspection Service. The number of slaughtered cattle was 825,951, of which (0.7\%) 5,395 were diagnosed as positive for the disease, through post-mortem inspection. The spatial scan analysis through the likelihood ratio showed the spatial distribution of bovine cysticercosis concentrated in defined a geographic area less likely to have occurred by chance, with an estimated risk of 13.6. This specific area encompasses 101 municipalities that belong to Itapetinga, Litoral Sul, Médio Rio de Contas, Vitória da Conquista and Extremo Sul Territories of Identification in Bahia State.
\end{abstract}

Keywords: bovine cysticercosis, spatial analyst, geographical distribution

\section{INTRODUÇÃO}

O complexo teníase/cisticercose envolvendo a larva infectante da Taenia saginata e os bovinos têm caráter zooantroponótico, com consideráveis reflexos negativos para o agronegócio e para a saúde pública (Marques et al., 2008). O regime de criação dos bovinos, somado ao baixo nível socioeconômico-cultural da população e à

Recebido em 13 de março de 2011

Aceito em 22 de maio de 2012

*Autor para correspondência (corresponding author)

E-mail: lucianacardim@yahoo.com.br precariedade das condições sanitárias, contribui para a contaminação das pastagens e mantém uma relação direta com a ocorrência da cisticercose entre os bovinos. A inter-relação desses animais com os seres humanos no campo passa a ser o principal responsável pela manutenção da endemia.

Apesar de o valor oficial da produção agropecuária brasileira ser da ordem de R\$239,8 
bilhões (2008), a elevada prevalência da cisticercose bovina, em torno de $6 \%$, acarreta nítida perda econômica, afetando diretamente a indústria da carne, que sofre depreciação de seu valor entre 10 e 15\% (Thakur, 1979; GonzalezLuarca, 1984; Santos, 1996). No estado da Bahia, que contribui com $17,6 \%$ da produção de carne bovina do país e ocupa a sétima posição no ranking nacional (Tsunechiro et al., 2010), a prevalência entre 0,82 e 1,74 também traz danos expressivos à sua pecuária (Gouvea, 2002; Arçari, 2008; Santos et al., 2008).

A prevalência da cisticercose no país tende a ser subestimada, pois baseia-se, principalmente, nos registros obtidos de inspeção post mortem, que é um método considerado de baixa sensibilidade, especialmente em infecções leves. Apesar das limitações, este método funciona como um indicador precoce do grau de infecção em uma determinada propriedade ou área geográfica (Minozzo et al., 2004; Pereira et al., 2006; Souza et al., 2007). Outra dificuldade para a estimativa da prevalência nacional decorre do fato de que os registros são restritos aos Serviços de Inspeção Federal (SIF), que fiscalizam apenas $49 \%$ dos animais abatidos, deixando de ser contabilizados os animais abatidos em matadouros municipais, estaduais e em locais sem inspeção (Rodrigues, 1993; Moreira et al., 2002; Dorny e Praet, 2007).

Os animais acometidos pela cisticercose não evidenciam os sintomas clínicos da doença. No entanto, esta é a parasitose mais diagnosticada em matadouros frigoríficos e a principal causa de condenações, sequestros e aproveitamentos condicionais de carcaças, gerando severos prejuízos econômicos à cadeia produtiva da carne bovina do país, com estimativas anuais de $\mathrm{R}$ \$ 24,5 milhões de perdas (Brasil, 1952; Pereira et al., 2006; Santos et al., 2008). Segundo Bonfim (2004), a presença de cistos vivos na carcaça do animal representa um deságio de até $65 \%$ do valor do bovino abatido e resistências de alguns abatedouros em comprar animais procedentes de propriedades infectadas.

A positividade da cisticercose bovina, com base em números absolutos de ocorrência, possibilita a interpretação equivocada da distribuição espacial da doença, visto que regiões com concentrações altas desses eventos são facilmente visualizadas e nem sempre representam as áreas de maior risco. Tais fatos sinalizam para a necessidade de renovação da abordagem. A utilização do geoprocessamento, associado à estatística espacial, vem se estabelecendo como de importância para a saúde pública e para o agronegócio, ao identificar áreas de risco para intervenção imediata, minimizando custos e racionalizando as ações de prevenção. Assim, este trabalho teve como objetivo utilizar as técnicas do geoprocessamento e a análise espacial de varredura, para identificação de áreas de risco para o Cysticercus bovis no estado da Bahia.

\section{MATERIAL E MÉTODOS}

O estudo foi desenvolvido no estado da Bahia, cuja extensão territorial é de $564.692,669 \mathrm{~km}^{2}$ e comporta 417 municípios agrupados, administrativamente, em 26 Territórios de Identidade, que consistem em representações espaciais de áreas com características comuns (Bahia, 2007; Fig. 1).

A vasta extensão territorial do estado da Bahia ostenta a sétima posição nacional do país em número de bovinos, com o rebanho aproximado de 10.528.419 cabeças de gado, representando $37 \%$ da população bovina da região Nordeste e $5 \%$ da população do país (Brasil, 2011). Grande parte do rebanho bovino é constituída por animais com aptidão para corte, com algumas particularidades de cunho regional (Bahia, 2006). Entretanto, a cadeia produtiva ainda é muito heterogênea em virtude da permanência de estruturas arcaicas em alguns municípios. $\mathrm{O}$ setor do agronegócio contribui com $25,4 \%$ para o produto interno bruto (PIB) baiano (Guilhoto et al., 2007), e a cisticercose aparece nesse cenário como um fator limitante para o crescimento da cadeia produtiva, com consequentes reflexos negativos no agronegócio.

O banco de dados utilizado neste estudo foi composto com base em informações sobre o quantitativo total de bovinos abatidos pelos seis matadouros frigoríficos com serviço de inspeção federal, localizados nos municípios de Barreiras, Feira de Santana, Itapetinga, Jequié, Simões Filho e Teixeira de Freitas; sobre o número de animais diagnosticados como positivos para a cisticercose, pelo método de inspeção post mortem, verificando-se a presença de cistos viáveis (vivos) ou degenerados (calcificados); e sobre os municípios de procedência dos animais 
abatidos, no período de 2006 a 2007, referentes a 21 dos 26 territórios de identidade do estado, por disporem de informações completas. A população bovina estimada para os municípios da Bahia foi obtida do Censo Agropecuário do Instituto Brasileiro de Geografia e Estatística (Brasil, 2006), e a positividade da cisticercose bovina foi calculada pela equação: número de animais positivos / número de animais abatidos $\mathrm{x}$ 100. A malha cartográfica digital da área de estudo foi composta por mapas de divisão política dos municípios baianos, em escala original de 1:1.500.000 (Brasil, 2007) e base territorial administrativa do estado (Bahia, 2005).

Para a detecção de aglomerados de risco para cisticercose bovina, foi utilizada a estatística espacial de varredura (Kulldorff e Nagarwalla, 1995), que se fundamenta na razão da máxima verossimilhança entre as áreas. Assim, um aglomerado de risco nada mais é que um grupo de eventos limitados geograficamente, em concentração e tamanho, e de risco distinto, de modo que seja improvável sua ocorrência ao acaso. Para análise dos dados e cálculo do risco relativo (RR), com nível de significância de 99\%, utilizou-se o software SaTScan ${ }^{\mathrm{TM}}$ versão 8.0, disponível gratuitamente na internet (http:॥www.satscan.org), e considerou-se as seguintes variáveis, agrupadas por território de identidade: população bovina/ano, número de casos de cisticercose bovina/ano e coordenadas dos centroides. Conforme recomendado por Kulldorff (2009), o software foi programado para realizar a análise puramente espacial (quando os casos ocorrem em uma mesma região ou espaço) e o intervalo de tempo anual; obedecer ao modelo de distribuição de probabilidade de Poisson (em que a distribuição é heterogênea e os eventos são raros em relação à população); considerar aglomerados com $50 \%$ da população bovina sob risco de adquirir a cisticercose (quando as taxas ou a prevalência da doença são baixas ou desconhecidas); submeter a análise à replicação de Monte Carlo de 9.999 vezes.

Os mapas temáticos foram elaborados com o auxílio do software ArcMap versão 9.1.

\section{RESULTADOS E DISCUSSÃO}

No presente estudo, de janeiro de 2006 a dezembro de 2007, foram abatidos 825.951 bovinos em seis matadouros frigoríficos com serviço de inspeção federal, dos quais 5.395 foram diagnosticados para cisticercose, com positividade de $0,7 \%$ entre os animais abatidos (Fig. 2). Não foram contabilizados os dados de animais abatidos em matadouros estaduais $\mathrm{e}$ municipais.

Considerando-se que o deságio atribuído ao animal positivo pode chegar a $65 \%$ (Bonfim, 2004), observa-se o poder desagregador da presença da doença para a cadeia produtiva baiana, visto que a bovinocultura de corte representa a atividade de maior desempenho econômico do estado (Bahia, 2006).

A forma de produção, as condições sanitárias inadequadas e o baixo nível socioeconômicocultural contribuem maciçamente para a persistente disseminação dessa doença parasitária. Em relação aos animais, o conhecimento sobre a prevalência da cisticercose ainda é falho em virtude da baixa notificação e da ausência de dados sistemáticos, confiáveis e passíveis de comparação.

Nesse contexto, os matadouros desempenham dois papéis primordiais para a saúde pública. Participam na prevenção da teníase humana, por meio da destinação apropriada de carcaças e órgãos bovinos cisticercóticos, e atuam também como fonte de dados estatísticos e nosográficos (Ungar e Germano, 1992; Pereira et al., 2006), que são sinalizadores para a vigilância sanitária, pois permitem identificar as áreas de ocorrência da doença para o direcionamento das ações de controle e de prevenção.

A distribuição geográfica do binômio teníasecisticercose não é obrigatoriamente uniforme no país, podendo existir, dentro de uma mesma região geográfica, áreas livres e outras com baixa ou alta endemicidade (Fernandes et al., 2002; Moreira et al., 2002), o que foi, também, observado neste estudo. A análise espacial de varredura identificou um aglomerado, do tipo primário (maior verossimilhança) de casos de bovinos infectados (Fig. 3), estatisticamente significante $(\mathrm{P}=0,0001)$, formado pelos 101 municípios que compõem os territórios de identidade de Itapetinga, Litoral Sul, Médio Rio de Contas, Vitória da Conquista e Extremo Sul, com 13, 27, 16, 24 e 21 municípios, respectivamente. 


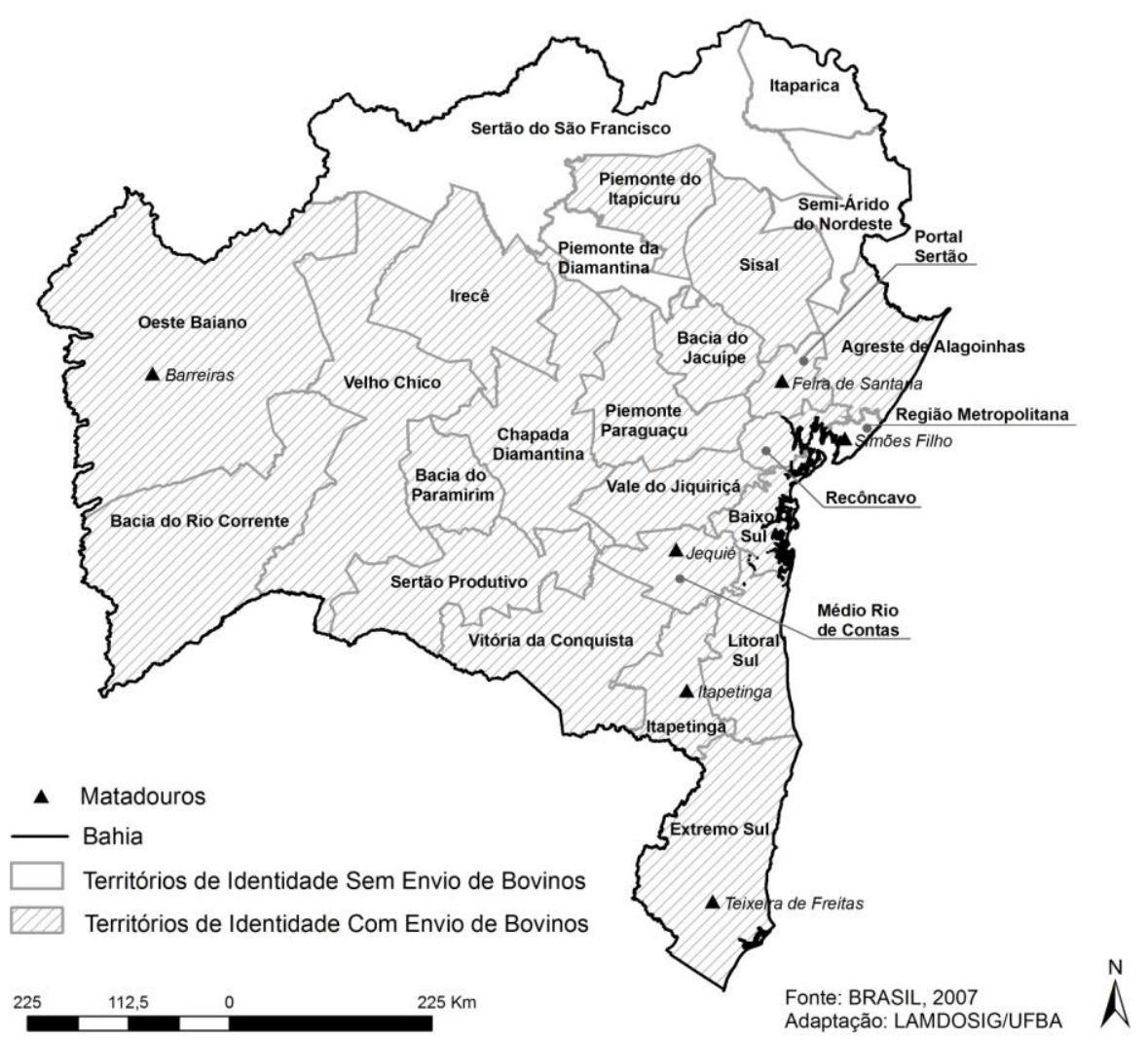

Figura 1. Territórios de identidade do estado da Bahia e matadouros frigoríficos sob o serviço de inspeção federal.

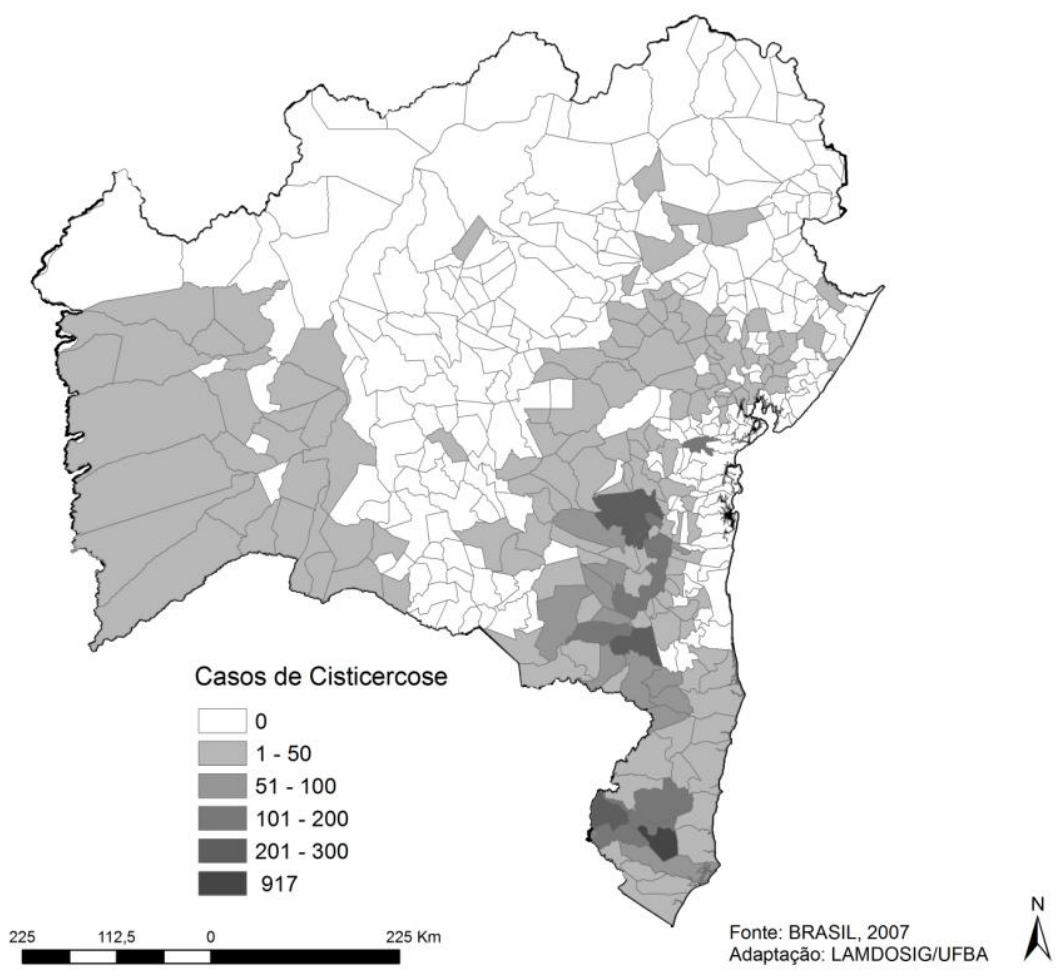

Figura 2. Casos de cisticercose bovina por município no estado da Bahia. 


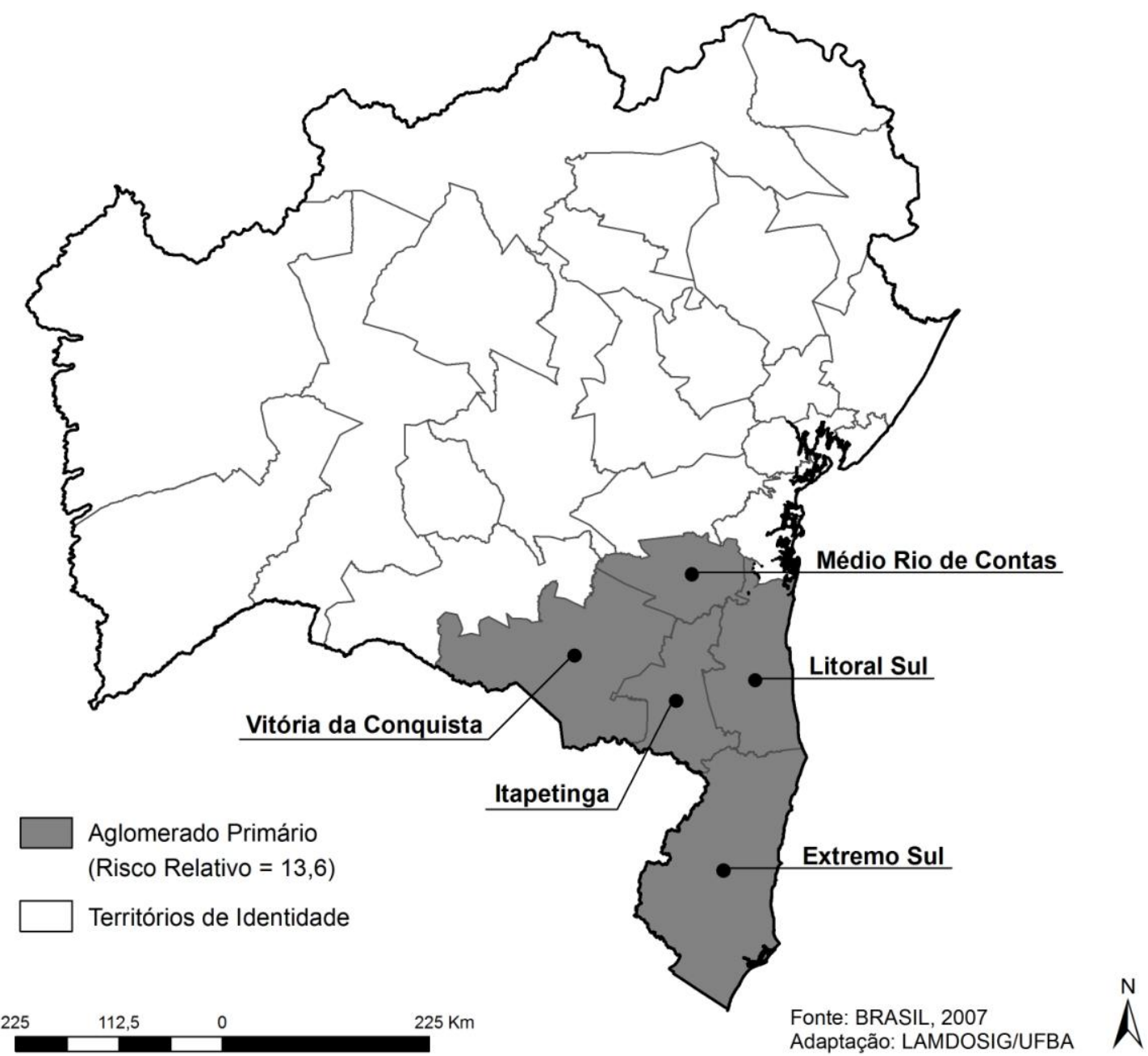

Figura 3. Aglomerado de risco para a cisticercose bovina no estado da Bahia.

Foram registrados nesse aglomerado 4.752 casos de cisticercose bovina, quando sob a hipótese nula, era esperado o número aproximado de 1.900 casos da doença, numa relação entre observados e esperados de 2,5. Nos territórios de identidade que compõem o referido aglomerado, a população bovina apresenta o risco relativo de contaminação pela cisticercose de 13,6 em relação aos demais territórios, o que possivelmente pode ser explicado, por estas áreas apresentarem o maior efetivo bovino do estado, altas densidades de animais e 50\% (3/6) dos matadouros sob inspeção federal instalados no estado da Bahia, os quais recebem, indiscriminadamente, animais oriundos de outros territórios para abate (Fig. 4). A opção de envio de animais para estes estabelecimentos de inspeção federal, por parte do produtor, pode advir de questões mercadológicas, valor econômico do peso vivo, serviço de fiscalização sanitária, restrições higiênicosanitárias, distância do município ao matadouro, entre outros. 


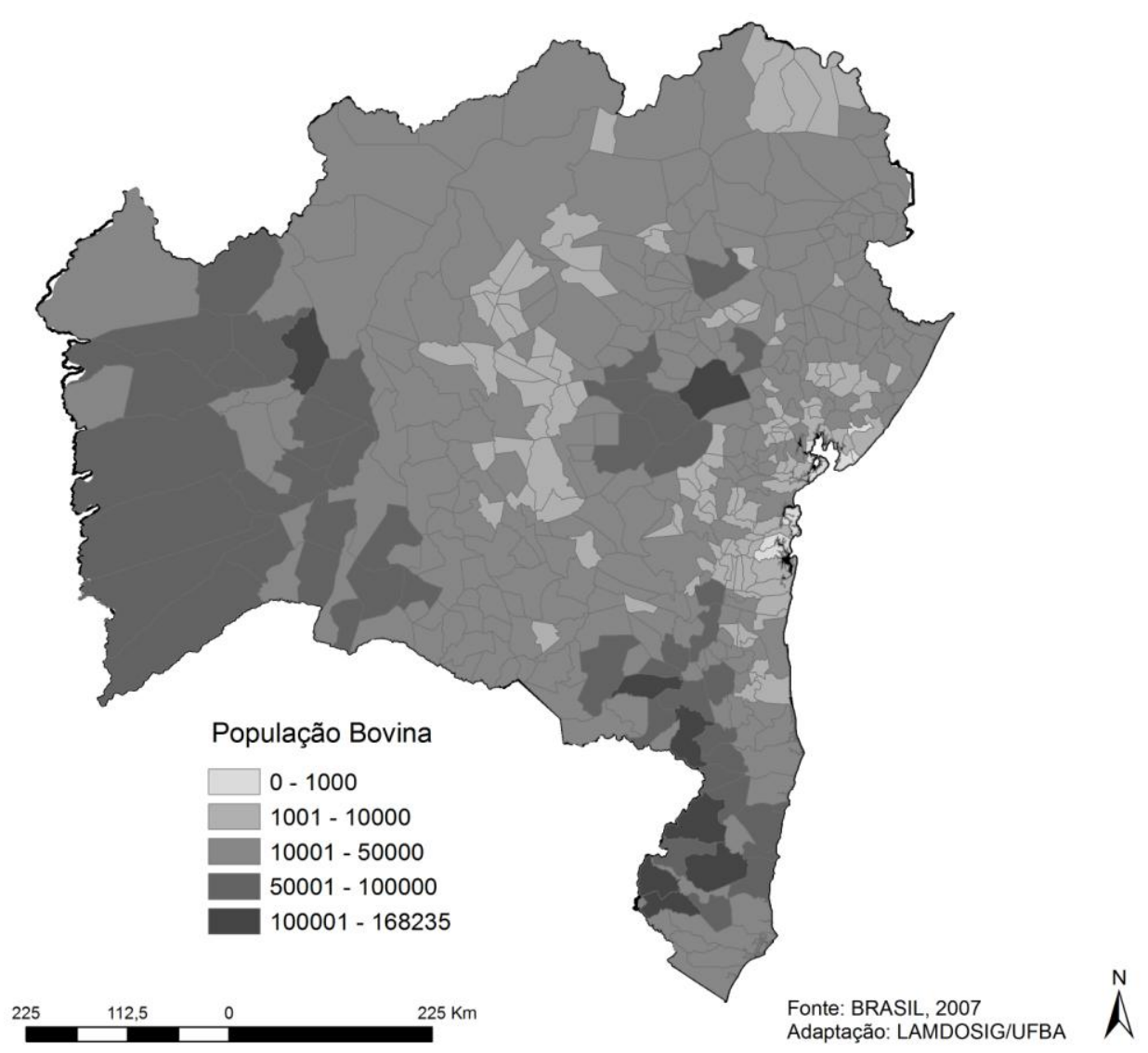

Figura 4. População bovina por município no estado da Bahia.

Dentre os cinco territórios pertencentes ao aglomerado, o Médio Rio de Contas apresentou o maior risco relativo $(8,1)$, seguido por Extremo Sul $(4,4)$, Itapetinga $(2,9)$, Vitória da Conquista $(1,1)$ e Litoral Sul $(0,5)$. Os três territórios de maior risco possuem, dentro das suas áreas geográficas, os matadouros de Itapetinga, Jequié e Teixeira de Freitas, o que pode ter contribuído para os resultados encontrados.

Na Fig. 5 observa-se a distribuição dos casos de cisticercose por município, que oscilou de 0 a 917, com destaque para os municípios de Itapetinga (217), Jequié (246) e Teixeira de Freitas (917), os quais possuem matadouros sob inspeção federal, e também estão inseridos nos três territórios de identidade que apresentaram os maiores riscos para esta parasitose. $\mathrm{O}$ fato de 32 municípios serem classificados como áreas silenciosas ou sem registro de casos não representa necessariamente ausência da doença, especialmente quando existem evidências de subnotificação, quer pela falta de estabelecimentos oficiais de inspeção (federal, estadual e municipal), ou apenas pela presença de inspeção estadual ou municipal, ou pela ocorrência do abate clandestino.

Cabe salientar que os municípios sem registros de casos retratam a situação da maioria das áreas geográficas do estado da Bahia, onde aproximadamente $59 \% \quad(246 / 417)$ de seus municípios não dispõem de dados sobre a doença (subnotificação), já que não enviam bovinos para abatedouros com SIF, sendo também classificadas como áreas de risco desconhecido. Outros dois agravantes desta situação dizem respeito à existência do abate clandestino, que acarreta um sério problema à saúde pública e danos à economia, e ao reduzido número de matadouros oficiais (federal, estadual e municipal) para o estado de grandes dimensões territoriais. 

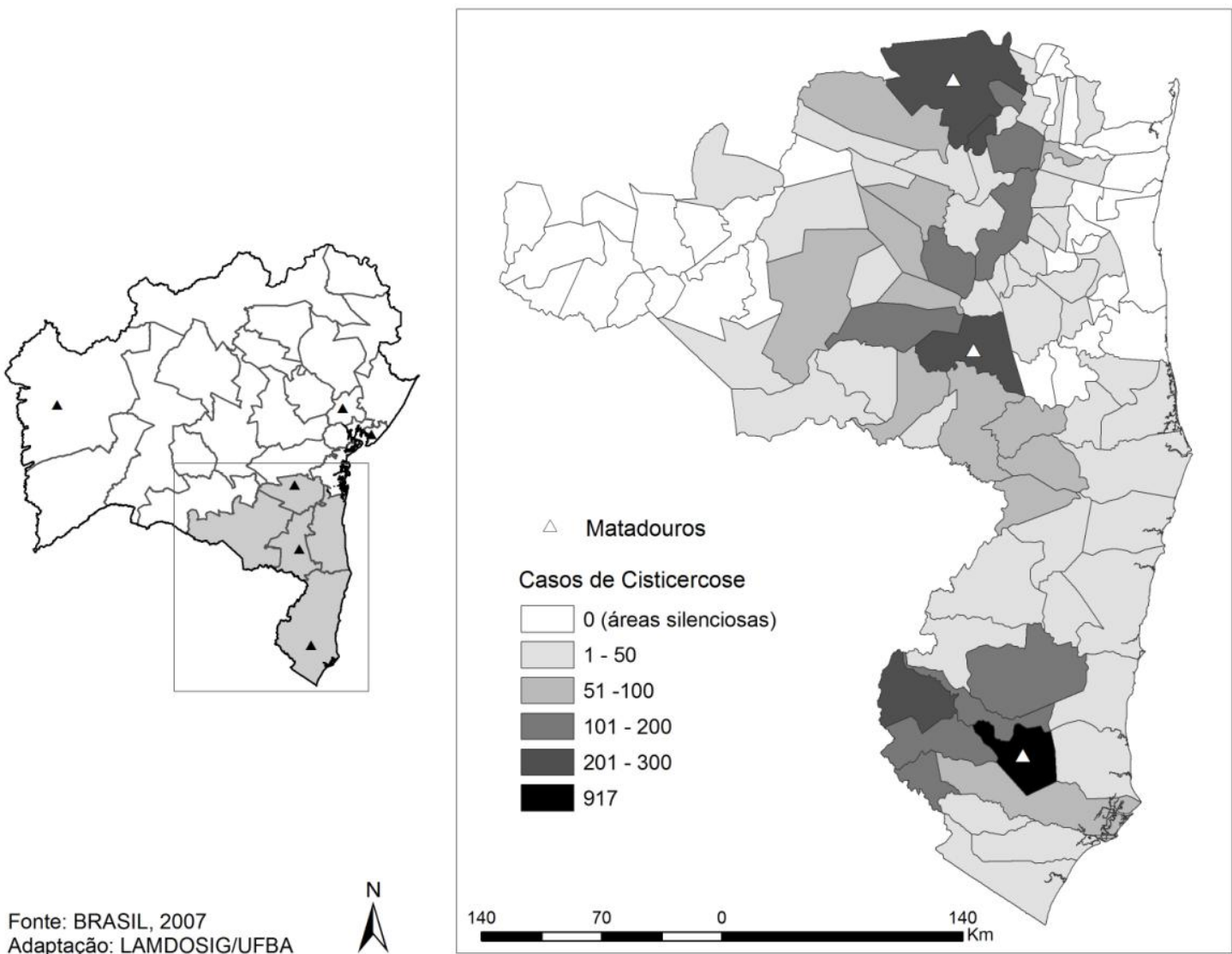

Adaptação: LAMDOSIG/UFBA

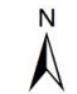

Figura 5. Número de casos de cisticercose bovina por município do aglomerado primário.

O espaço geográfico englobado pelo aglomerado registrou $88,1 \% \quad(4.752 / 5.395)$ dos casos de cisticercose bovina detectados no estado pelo serviço de inspeção federal, sendo $46,3 \%$ $(2.200 / 4.752)$ no Extremo Sul, $24,3 \%$ (1.157/4.752) em Itapetinga, $19,8 \%(940 / 4.752)$ no Médio Rio de Contas, 7,0\% (332/4.752) em Vitória da Conquista e 2,6\% (123/4.752) no Litoral Sul.

Levando-se em consideração a multiplicidade de fatores que estão interligados na cadeia de transmissão dessa doença, novos estudos são necessários para se analisar a influência de fatores ambientais, econômicos, socioculturais, higiênico-sanitários dos sistemas de exploração animal, fiscalização sanitária nos âmbitos estadual e municipal, entre outros, que, certamente, poderão fomentar as ações de controle e de prevenção, para que a cisticercose não se torne um entrave ainda maior para $o$ agronegócio baiano e para o desenvolvimento produtivo da região.
Visto que os dados disponibilizados pelo MAPA/BA foram restritos à relação de abate dos animais por município de procedência, tipo de doenças detectadas e seu percentual, não foi possível analisar outras covariáveis referentes aos bovinos parasitados, como sexo, idade, raça, órgãos examinados, intensidade de infestação, percentual de descarte, dentre outros, que se configuram como limitação deste trabalho.

\section{CONCLUSÕES}

Neste estudo, foi identificado um aglomerado de casos de cisticercose bovina, de máxima verossimilhança, ou seja, com a menor probabilidade de ter ocorrido ao acaso, e sob o risco estimado de 13,6, compondo uma área geográfica definida representada por 101 municípios baianos pertencentes aos territórios de identidade Extremo Sul, Itapetinga, Médio Rio de Contas, Vitória da Conquista e Litoral Sul. 


\section{AGRADECIMENTOS}

Ao fiscal agropecuário federal Dr. Edson Sales, pela atenção, presteza e disponibilidade dos dados do Ministério da Agricultura Pecuária e Abastecimento/Bahia.

\section{REFERÊNCIAS}

ARÇARI, A.T. Cisticercose bovina: uma revisão e estudo com bovinos abatidos em frigorífico com Inspeção Federal, no ano de 2007, em Teixeira de Freitas - Ba. 2008. 30p. Monografia (Especialização) - Curso de Pós-graduação em Defesa e Vigilância Sanitária Animal, Universidade Castelo Branco, Rio de Janeiro. 2008.

BAHIA. Plano Estadual de Recursos Hídricos. PERH, 2005. Disponível em: 〈http:// www.srh.ba.gov.br〉 Acessado em: 9 jan. 2009.

BAHIA. Secretaria da Agricultura, Irrigação e Reforma Agrária. O agronegócio baiano 1995-2006. Salvador, SEAGRI, 2006, 108p. Disponível em: <http://www.seagri.ba.gov.br/relatorio_12anos.pdf > Acessado em: 21 out. 2011.

BAHIA. Secretaria do Planejamento do Estado da Bahia. Territórios de Identidade, 2007. Disponível em <http://www.seplan.ba.gov.br/mapa.php〉. Acessado em: 15 jan. 2010.

BONFIM, L.M. Os perigos e prejuízos da cisticercose bovina. REHAGRO, Belo Horizonte, 16 jan. 2004. Disponível em: <http://www.rehagro.com.br/siterehagro/publicacao.d o? cdnoticia=503 > . Acessado em: 10 mar. 2010 .

BRASIL. Ministério da Agricultura, Pecuária e Abastecimento. Regulamento da inspeção industrial e sanitária de produtos de origem animal. RIISPOA, Rio de Janeiro, 29 mar. 1952. Disponível em: <http://www.abef.com.br/Legislacoes/decreto30691.p df>. Acessado: em 27 mar. 2010.

BRASIL. Instituto Brasileiro de Geografia e Estatística. Censo Agropecuário. 2006. Disponível em: <http://www.ibge.gov.br/home/estatistica/economia/ag ropecuaria/censoagro/2006/defaulttab_censoagro.shtm >. Acessado em: 07 abr. 2009.

BRASIL. Instituto Brasileiro de Geografia e Estatística. Mapeamento Topográfico, 2007. Disponível em: <http://www.ibge.gov.br/home/geociencias/default_pr od.shtm> Acessado em: 20 abr. 2008.

BRASIL. Instituto Brasileiro de Geografia e Estatística - Pesquisa Pecuária Municipal, 2011. Disponível em $<$ http://www.sidra.ibge.gov.br/bda/tabela/protabl.asp? $\mathrm{c}=73 \& \mathrm{z}=\mathrm{t} \& \mathrm{o}=24 \& \mathrm{i}=\mathrm{P}>$. Acessado em: 1 nov. 2011.
DORNY, P.; PRAET, N. Taenia saginata in Europe. Vet. Parasitol., v.149, p.22-24, 2007.

FERNANDES, J.O.M.; SILVA, C.L.S.P.; BORGES, J.H.R. et al. Prevalência da cisticercose bovina em animais abatidos em estabelecimento sob regime de inspeção federal no município de Andradina - SP. Cien. Agr. Saúde, v.2, p.14-17, 2002.

GONZALEZ-LUARCA, E. Situação atual do complexo teníase humana cisticercose nas Américas. Comunicações científicas da Faculdade de Medicina Veterinária e Zootecnia da Universidade de São Paulo, v.8, p.222-226, 1984.

GOUVEA, A.A.L. Cisticercose bovina. Incidência e aspectos histopatológico em bovinos abatidos no matadouro frigorífico no município de Simões Filho BA. 2002. 48p. Monografia (Graduação) - Escola de Medicina Veterinária, Universidade Federal da Bahia, Salvador, 2002.

GUILHOTO, J.J.M.; ASSUMPÇÃO, M.; MÓDOLO, D.B.; IMORI, D. O PIB do agronegócio no Brasil e no estado da Bahia. In: CONGRESSO DA SOCIEDADE BRASILEIRA DE ECONOMIA, ADMINISTRAÇÃO E SOCIOLOGIA RURAL, 14., 2007, Londrina. Anais... Londrina: [s.n.] 2007. p.1-19. (Resumo Expandido).

KULLDORFF, M. SaTScan ${ }^{\mathrm{TM}}$ User Guide, fev. 2009. Disponível em: <http://www.satscan.org/techdoc.html>. Acessado em: 02 jun. 2009.

KULLDORFF, M.; NAGARWALLA, N. Spatial disease clusters: detection and inference. Statistics in Medicine, v.14, p.799-810, 1995.

MARQUES, G.M.; BUZI, K.A.; GALINDO, L.A. et al. Avaliação dos Registros de Condenação por Cisticercose em bovinos abatidos em frigoríficos da região Centro Oeste do estado de São Paulo - 1996 a 2000. Vet. e Zootec., v.15, p.114-120, 2008.

MINOZZO, J.C.; SOCCOL, V.T.; OLORTEGUI, C.C. et al. Teste imunoenzimático (enzyme-linked immunosorbent assay) para diagnóstico da cisticercose bovina e estudo da cinética de produção de anticorpos contra Cysticercus bovis. Cienc. Rural, v.34, n.3, p.857-864, 2004.

MOREIRA, M.D.; ALMEIDA, L.P.; REIS, D.O. Cisticercose bovina: um estudo com bovinos abatidos em matadouro municipal de Uberlândia, MG. Hig. Aliment., v.16, p.37-41, 2002.

PEREIRA, M.A.V.C.; SCHWANZ, V.S.; BARBOSA, C.G. Prevalência da Cisticercose em Carcaças de Bovinos Abatidos Matadouros-Frigoríficos do Estado do Rio de Janeiro, Submetidos ao Controle do Serviço de Inspeção Federal (SIF-RJ), no Período de 1997 a 2003. Arq. Inst. Biol., v.73, p.83-87, 2006. 
RODRIGUES, L.V.C. Inspeção Sanitária e Critérios de Julgamento da Cisticercose Bovina Calcificada. Infecção leve. Cienc. Rural, v.23, p.339-344, 1993.

SANTOS, I.F. O Cysticercus bovis. Forma larvar da Taenia saginata pode infectar o homem? 1996. In: SANTOS, J.P. Prevalência de cisticercose bovina em matadouro frigorífico sob inspeção estadual (SIE) em Santa Catarina. 2008. 37f. Monografia (Especialização) - Curso de Pós-graduação em Higiene e Inspeção de Produtos de Origem Animal, Universidade Castelo Branco, Rio de Janeiro. 2008.

SANTOS V.C.R.; RAMOS, E.T.R.; ALMEIDA FILHO, F.S. et al. Prevalência da cisticercose em bovinos abatidos sob inspeção federal no município de Jequié, Bahia, Brasil. Cienc. Anim. Bras., v.9, p.132139, 2008.
SOUZA, V.K.; PESSÔA-SILVA, M.C.; KOWALCZUK, M. et al. Regiões Anatômicas de Maior Ocorrência de Cysticercus bovis em Bovinos Submetidos à Inspeção Federal em MatadouroFrigorífico no Município de São José dos Pinhais, Paraná, de Julho a Dezembro de 2000. Rev. Bras. Parasitol. Vet., v.16, p.92-96, 2007.

THAKUR, A.S. Teníase e cisticercose. Buenos Aires: OPAS/OMS, Centro Pan Americano de Zoonosis, 1979. 13p.

TSUNECHIRO, A; COELHO, P.J.; MIURA, M. Paraná Liderou o Ranking do Valor da Produção Agropecuária do Brasil em 2008. Análises $e$ Indicadores do Agronegócio, v.5, p.1-4, 2010.

UNGAR, M.L.; GERMANO, P.M.L. Prevalência da cisticercose bovina no Estado de São Paulo (Brasil). Rev. de Saúde Pública, v.26, p.167-172, 1992. 